\title{
The Laser Technology: New Trends in Biology and Medicine
}

\author{
Luc G. Legres ${ }^{1 *}$, Christophe Chamot ${ }^{2 \#, ~ M a r i a n a ~ V a r n a ~}{ }^{3}$, Anne Janin ${ }^{1,4}$ \\ ${ }^{1}$ Inserm UMR S1165, Université Paris-Diderot, IUH, Paris, France \\ ${ }^{2}$ US8/UMS-3444, Bio Image Facility, PLATIM, Lyon, France \\ ${ }^{3}$ Inserm UMR_S979, ESPCI ParisTech, Institut Langevin, Paris, France \\ ${ }^{4}$ Service de Pathologie, Hôpital Saint-Louis, AP-HP, Paris, France \\ Email: luc.legres@sls.aphp.fr
}

Received 29 November 2013; revised 26 December 2013; accepted 23 January 2014

Copyright (C) 2014 by authors and Scientific Research Publishing Inc.

This work is licensed under the Creative Commons Attribution International License (CC BY).

http://creativecommons.org/licenses/by/4.0/

(c) (i) Open Access

\section{Abstract}

In fifty years, laser technology has made great progress, and its many applications make it essential in everyday life. However, this technology is still open to numerous developments. Across multiple applications, there is particular focus in the field of medicine, for diagnosis for tailored therapies, and as a research tool in biology. Whereas its use is now well-demonstrated in ophthalmologic and dermatologic treatments, and surgery, one of the most fascinating aspects of laser technology in the field of biology emerged in the late 1990s with the development of devices able to perform fine dissections of biological tissues using a laser beam. The so-called laser-associated microdissection offers a rapid, precise method of isolating and removing targeted cells or groups of cells from complex biological tissues. It represents the missing link between clinical observations and the intrinsic physiological mechanisms of biological tissues. The molecular examination of pathologically altered cells and tissues for DNA, RNA, and protein expression has revolutionized research and diagnosis in pathology, enabling assessment of the role of the cell type in the normal physiological or disease process. Alongside conventional diagnostic and therapeutic approaches, another field of application contribute to the development of targeted treatments at the nanoscale level of laser technology, mainly in the field of cancer, leading to design new and innovative strategies in drug delivery and image-guided surgery. Most of these approaches, but although not exhaustively, will be presented here.

\section{Keywords}

Laser; Biology; Microdissection; Molecular Biology; Forensic; Photo-Ablation; Nanotechnology; Cancer

\footnotetext{
"Member of "MicroLaser Biotech", the French laser microdissection network.

"Member of the RT-mfm network "MicroscopiePhotonique de Fluorescence Multidimensionnelle" from the MRCT of CNRS.
} 


\section{Introduction}

Laser-Light Amplified Stimulated Emission Radiation, unlike a standard light beam, is a source of monochromatic, coherent and unidirectional light. Lasers are installed widespread in everyday life across multiple numerous applications: CD and DVD, barcode scanners, entertainment, welding or cutting in industry, aid to fire control or alignment of roads and tunnels. In the medical field, lasers are diagnostic and therapeutic instruments that offer a whole range of solutions. The laser which enables for greater surgical precision is less invasive and promotes healing time or cure. This technique is generally much less traumatic than traditional surgical techniques. The first use of lasers in medicine was to damage the retina to understand ocular injury due to accidental exposure [1]. Since the first ruby laser, several devices have been improved placing ophthalmology at the forefront of medical specialties using this technology. The laser has also many applications in the field of biology. Researchers take the technology to its limits by playing on two main parameters, the short laser pulses-to the femtosecond-, and energy beams. Since then, pulsed lasers have become increasingly popular for their ability to ablate biological tissue. For patient diagnosis and experimental studies, biological tissue can be either analyzed under a microscope after immuno-histostaining or crushed for further molecular analysis. Laser-Assisted microdissection (LAM) provides a valuable link between these two approaches. It gives new insights into cellular mechanisms, genetic disorders, tumor biomarker identification patient-tailored therapy. The development of light-absorbing nanoparticles that are nontoxic to biological tissue has provided further potential for a more targeted delivery of heat with minimal damage to healthy tissue. At an appropriate wavelength, exposure of a nanoparticle to a laser can trigger a photothermal effect in the particle whereby electronic oscillations at the particle surface are converted to heat [2].

\section{Lasers in Medicine}

\subsection{Laser in Ophthalmology}

Its advantages have been demonstrated in the treatment of myopia and cataract where they enable patients with visual impairment to regain a clear vision and forget the stress of wearing glasses or contact lenses [3].

\subsection{Lasers in Dermatology}

Treatment of vascular lesions such as angiomas, telangiectasias, spider naevi, treatment of pigmented lesions (brown spots, naevus of ota, freckles) and tattoo or hair removal targeting the melanin stored in the hair follicles in order to destroy the hair matrix to enable permanent hair removal [4].

\subsection{Laser in Surgery}

Laser surgery has the advantage of reducing the risk of infection and it promotes healing. It is used in cosmetic surgery to erase cellulite and superficial wrinkles. Often less invasive than conventional surgery, laser surgery is however not without risks [5].

\subsection{Lasers in Other Applications}

Lasers can also be used in dentistry (gum care and treatment of tooth decay) [6] and phlebology (treatment of varicose veins) [7].

\section{In What a Laser Consists?}

A laser consists of a cavity with a mirror at each end and a gain medium, placed between the two mirrors. Excited by an energy source, the medium emits light which circulates between the mirrors and is amplified at each passage. One of the mirrors is slightly transparent to enable the laser beam to exit from the cavity. Lasers can be distinguished according to the nature of the amplifying medium: gas, liquid or solid:

\subsection{Gas Lasers (Argon, Krypton, etc ....)}

- Use of lasers in the treatment of various types of glaucoma is an important tool in ophthalmic practice. Both Argon and YAG lasers are now commonly used in the treatment of angle-closure and open-angle glaucoma 
[8]. The laser Krypton has applications close to those of argon and is useful to restrict bleeding [9].

- The $\mathrm{CO}_{2}$ laser belongs to the gas lasers. It is the excitement of the gas that produces a laser beam. This radiation is located in the invisible range (infrared laser to $1060 \mathrm{~nm}$ ). The effects of this type of laser will vary depending on their use. It has ablative properties that are essential biological effects for instance a volatilization effect of the surface of the epidermis and a thermal effect able of shortening the collagen fibers (tightening effect on the skin). These properties are used to treat acne scars type, healing [10] and to obtain a rejuvenating effect on the face [11] [12]. The $\mathrm{CO}_{2}$ laser seems most useful in ophthalmology to vaporize lymphangioma and capillary haemangioma and to provide hemostasis in patients with bleeding disorders [13]. Although $\mathrm{CO}_{2}$ lasers have been available for some time, they are now back on the dermatological field with the possibility leaving healthy areas of skin between impacts, which enable a very fast recovery and shorter healing time [14]. The efficacy and safety of fractional $\mathrm{CO}_{2}$ laser has also been evaluated in eyelid tightening and periorbital wrinkles [15]. $\mathrm{CO}_{2}$ lasers produce smoke. They require more stringent precautions than in the use of other lasers. In addition, $\mathrm{CO}_{2}$ lasers may require stronger anesthetic methods than for other lasers. The prolonged recovery time and risk of potential side effects make them less attractive alternative treatments [16].

\subsection{Liquid Dye Lasers}

Dye lasers produce their light radiation by stimulating a liquid dye. They are mostly "tunable" between 550 and $590 \mathrm{~nm}$. Their light is visible. Dye lasers are often used in vascular indications: treatment of angiomas in children and infants, treatment of spider naevi, treatment of rosacea [17] [18]. Less frequently, this type of laser is used in other diseases such as psoriasis where it is effective against new lesions [19] [20].

\subsection{Solid-State Lasers}

The medium is a crystal (ruby, sapphire titanium ...), glass (Neodymium glass...) or ceramic. In a non-exhaustive list, there are also laser diodes, such as those found in the CD.

\section{- Alexandrite laser}

The alexandrite laser is based on the production of light using a crystal of alexandrite. The light is calibrated to a specific wavelength of 755 nanometers (deep red). This wavelength is strongly absorbed by the melanin in the skin and in particular that of the hair. It is this property that is used to heat the hair and help to destroy it [21] [22]. Laser hair removal of the eyebrows can lead to ocular damage and should be avoided [23].

\section{- YAG lasers}

These are Yttrium Aluminum Garnet-YAG lasers producing very short exposure times of the order of the nanosecond. These particular lasers are indicated for the treatment of age spots and tattoos ablations.

- The Neodymium-doped YAG (Nd:YAG) laser is calibrated on a wavelength of 1064 nanometers, in the infra-red range. The Nd:YAG laser is relatively versatile, with the ability to penetrate deep into the skin. It enables aesthetic treatment of superficial veins of the skin, acne, rosacea, warts, birthmarks. These lasers also have photorejuvenation properties [24] [25].

- Erbium-doped YAG (Er:YAG) lasers are closed to $\mathrm{CO}_{2}$ lasers, particularly for their abrasive properties. The light generated has a wavelength of $2940 \mathrm{~nm}$. They are used in photo rejuvenation, resurfacing, acne, scars, warts and also dentistry presenting a wavelength affinity with water (absorption peak $=3000 \mathrm{~nm}$ ). This enables efficient ablation of hard dental tissues without the risk of micro- and macro-fractures [26] [27]. The Er:YAG laser is used for ablation of the epithelium on the non-pigmented skin of the eyelid in preparation for melanocyte transplantation in the treatment of segmental eyelid vitiligo [28].

- The Potassium Titanyl Phosphate (KTP) laser is also a subclass of YAG laser. It is a Nd:YAG laser where a crystal possessing the property of dividing the wavelength by 2 is added. The KTP laser then emits light at a 532 nanometers wavelength (yellow green). The mechanism of KTP laser ablation remains unclear, but successful laser treatment of both vascular and non-vascular lesions has been described [29]. It is primarily used for vascular treatment and also has indications in the treatment of superficial pigmented lesions, pregnancy mask (melasma), dermatitis ocher, some pigmentation related to drugs, certain types of scarring or ulcers [30].

- The laser diode is based on the production of light by an electronic component called a diode. There are several types of diodes with different wavelengths between 800 and $900 \mathrm{~nm}$ (infrared). Diode lasers are most 
often used in hair removal and aesthetic vascular treatments applications [31] [32]. The laser diode is an effective treatment for patients with glaucoma [33].

\section{The Effects of Lasers on Biological Tissues}

After the text edit has been completed, the paper is ready for the template. Duplicate the template file by using the Save As command, and use the naming convention prescribed by your journal for the name of your paper. In this newly created file, highlight all of the contents and import your prepared text file. You are now ready to style your paper.

\subsection{Thermal Effects}

The laser on biological tissue results from the conversion of light to heat, heat transfer and a tissue reaction to the temperature and the duration of the heating [34]. This interaction leads to distortion or the destruction of a tissue volume. Depending on the degree to which time is heated, and the heating time, the thermal effect of the laser produces coagulation necrosis as in the treatment of angiomas with Nd:YAG laser, or volatilization as in the treatment of skin lesions with $\mathrm{CO}_{2}$ laser.

\subsection{Mechanical Effects}

They are obtained with lasers emitting extremely short pulses, in the nanosecond to picosecond range on very small surfaces, which causes a destructive shock wave mainly induced by the mechanism of explosive vaporization of the target as used to treat haemangiomas [35]. In this case, the vessels of the angioma explode, which explains the vessel wall rupture, and hemorrhage. This is also what happens during a tattoo removal when large fragments of pigment explode and give birth to smaller fragments.

\subsection{Photo-Ablation}

An effect that requires high-energy photons (wavelength less than $300 \mathrm{~nm}$ ), with extremely short pulses (10 ns to $100 \mathrm{~ns}$ ). It induces a clean ablation of tissue without thermal lesions. Photo-ablation is the most recent light-tissue interaction to be exploited clinically. It is used to treat corneal pathologies such as ulcers and scars, and its use in keratorefractive surgery has become a rapidly evolving field [36]. The operation is performed under local anesthesia (using topical drops). The first step of the procedure involves cutting a corneal flap surface (90 to 180 micrometers). Until the early 2000s, the most common way of cutting the corneal flap was the use of a microkeratome, a miniaturized and highly sophisticated mechanical device. This first very delicate cutting phase is now done by a laser, the femtosecond laser. The cutting of the corneal flap is achieved in about ten seconds, and then the refractive sculpture is carried out using an excimer laser. Excimer lasers are powered by a chemical reaction involving an excited dimer, or excimer, which is a short-lived dimeric or heterodimeric molecule formed from two atoms, at least one of which is in an excited electronic state. They typically produce ultraviolet light, and are used in LASIK (laser in situ keratomileusis) eye surgery (see video:

http://www.ophtalmologie.fr/operation-myopie-video-lasik.html). Commonly used excimer molecules include fluorine (emitting at $157 \mathrm{~nm}$ ) and noble gas compounds (Argon-193 nm, Krypton-222 nm, etc.). The femtosecond laser is the new scalpel for biologists. Since 2000, they have gradually become familiar with this tool, which opens up great prospects in life sciences [37].

\subsection{Photochemical Effects}

They are obtained with lasers emitting extremely short pulses, in the nanosecond to picosecond range on very small surfaces, which causes a destructive shock wave mainly induced by the mechanism of explosive vaporization of the target as used to treat haemangiomas [38]. In this case, the vessels of the angioma explode, which explains the vessel wall rupture, and hemorrhage. This is also what happens during a tattoo removal when large fragments of pigment explode and give birth to smaller fragments.

\section{Applications to Biological Tissues}

The lasers used in biology have a wavelength located either in the infrared range or in the ultra-violet range; 
they operate in continuous or pulse mode. The high power density and the precise location of the laser beam suits its application to the cutting of biological tissue. The high concentration of photons will destroy existing chemical bridges in the tissues.

\subsection{Laser-Assisted Microdissection}

Laser-assisted microdissection (LAM) is a well-established technology in molecular pathology, cell biology and oncology studies, where very small tissue samples must be isolated from the surrounding material in order to perform an analysis without risk of contamination. LAM overcomes the problem of the cellular heterogeneity that characterizes tissues. It aims to recover a target cluster of cells, or a single cell precisely selected under microscope guidance, from a complex tissue section (frozen or fixed by prior paraffin-embedding) for subsequent molecular analysis [39] [40] (Figure 1). With the advent of PCR (Polymerase Chain Reactions) techniques, a technique for million-fold amplification of a single DNA molecule, microdissection enables a molecular approach of biological tissues, but with the certainty of having a highly purified cellular material for the molecular studies. Over the past 15 years, this technique for isolating specific cells from a sample responds to the need for miniaturization of analytical techniques applicable to very small cell numbers. LAM devices have gradually become more user-friendly. A laser microdissector is composed of a microscope (upright or inverted) coupled to a laser beam (wavelength in the IR-infrared and/or UV-ultraviolet range) which operates under the control of a computer program. The development of this approach using a laser beam has greatly increased the precision and effectiveness of biological material collection (Figure 2).

Four laser-assisted microdissection systems are currently available, based on different operating principles (for review see Legrès et al. [41]).

- The LCM system (for Laser Capture Microdissection, PIXCEL II ${ }^{\circledR}$, and more recently the VERITAS ${ }^{\mathrm{TM}}$ system, both from Arcturus Engineering and now under the label of Life Technologies), was originally conceived and developed in 1996 as a research tool at the National Institutes of Health [42].

- The LMPC system (for Laser Microdissection and Pressure Catapulting) (3D-PALM Microlaser Technologies, Carl Zeiss MicroImaging Technologies, Munich, Germany) associates an inverted microscope with an ultraviolet laser (UV-A pulsed, wave length $335 \mathrm{~nm}$ ) [43].

- The LMD system (Leica Microsystems) is close to the LMPC system [44]. In this system, unlike the others, the tissue section remains stationary on the microscope and the UV laser beam moves over it when cutting.

- The MMI Caplift technology, called MMiCellcut ${ }^{\circledR}$ operates with a UV laser (wave length $335 \mathrm{~nm}$ ) on an inverted microscope [45].

For the LCM device, precise IR capture solid-state laser, near-IR $(810 \mathrm{~nm})$ and a basic cutting solid-state diode-pumped UV Laser (355 nm) are used separately in one single instrument. However, UV solid-state lasers $(355 \mathrm{~nm})$ are commonly used in each device. For the LMPC device, a gas laser operating in the ultraviolet range is used with molecular nitrogen as its gain medium, pumped by an electrical discharge. The LMD microsys-
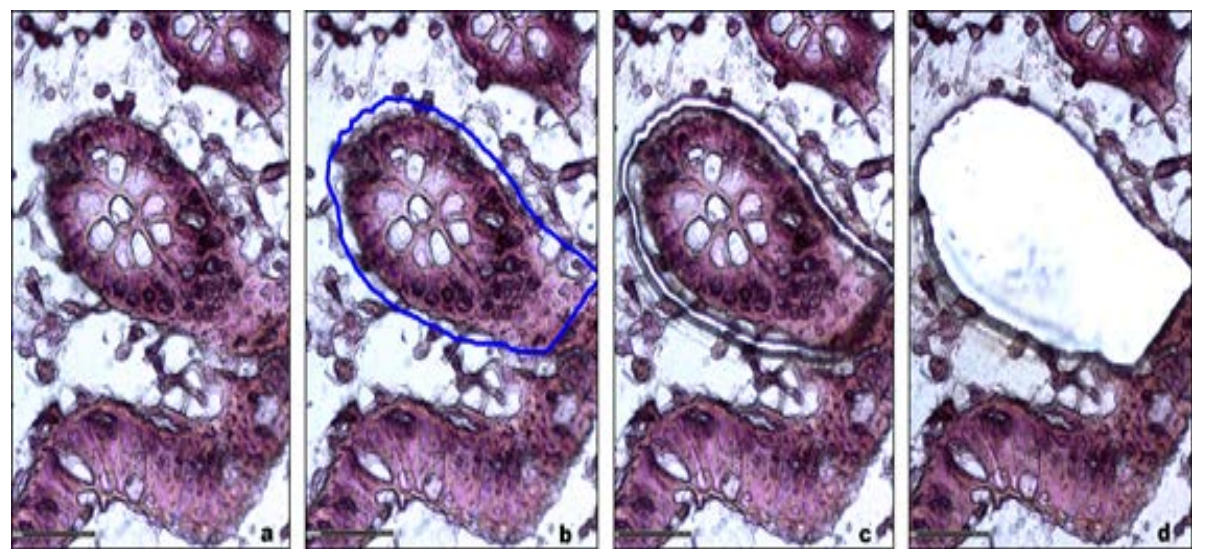

Figure 1. Chronological succession of steps showing the laser beam cutting of a biological tissue: (a) Scope display of the region to recover; (b) Selection of cells of interest through a graphical wizard on the computer (blue line); (c) Cut made by the laser beam along the path as defined above; (d) The region that has been selected and cut is then recovered for analyses. 


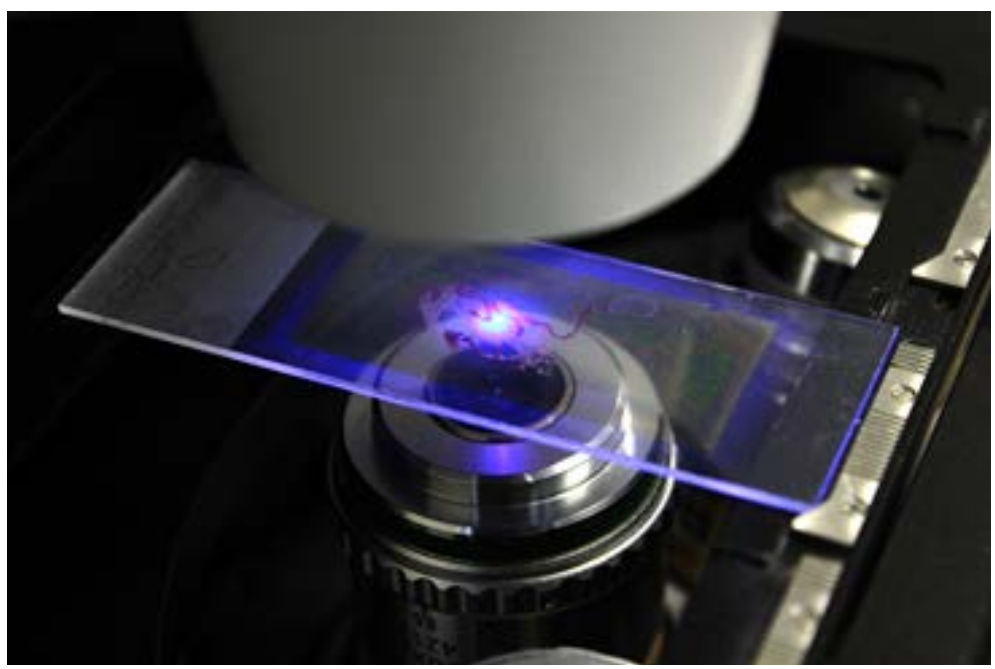

Figure 2. Blue light of a laser beam cutting a specific region, or cells of interest from a biological tissue laid after treatment on a microscope slide.

tem works with a diode-pumped solid-state UV laser. The MMI CellCut system dissects the areas of interest with an ultra-precise solid-state diode-pumped YAG Laser. The MMI CellManipulator uses a Nd:YAG infrared laser with a wavelength of $1064 \mathrm{~nm}$.

Neoplasia is the main field of application of this technique for selecting tissue, but other fields have gradually opened up to these new methodological approaches, for instance for micro-dissecting living cells from a cell culture with the possibility of re-culturing the isolated cells [46].

De Spiegelaere W et al. used this technique for the isolation of small tissue fractions from developing embryos [47]. Sethi et al. have described its usefulness in a case of renal amyloidosis in native and kidney transplant biopsies [48]. LAM will enable the establishment of "genetic fingerprints" of specific pathological lesions. Thus, from cell fragments, one of the most common applications of LAM has been the search for loss of heterozygosity $(\mathrm{LOH})$ in malignant tumors. Bertheau et al. showed that at least one-third of cases of LOH occuring in breast tumors remain clearly undiagnosed if the tissue has not been microdissected [49]. Cytogenetic studies, enabling analysis of the complex chromosome rearrangements that have been frequently detected in many malignancies and congenital diseases are also greatly facilitated by microdissection [50]. Proteomic analysis in tissue samples imposes certain rules in experimental protocols used for tissue processing [51]. In addition to the identification of new diagnostic and prognostic markers, this approach could help in establishing individualized treatments tailored to the molecular profile of a tumor [52]. This approach is even more powerful when it is combined with immuno-cytochemical staining using specific antibodies to label the cells of interest.

The value of LAM in forensic science cannot be underestimated [53]. DNA analysis has become the prime tool for identification of the source of biological traces [54]. Most reports focus on the use of LAM to isolate a single sperm from a vaginal smear for genetic analysis in the investigation of sexual assault, the first application described by Elliott et al. [55]. An even more challenging situation occurs when cells of a victim are much more abundant than the cells of the perpetrator. DNA analysis then becomes a crucial tool in suspect identification.

\subsection{The Optical Tweezers}

Laser tweezers, often known as optical tweezers or optical traps, enable the capture and micromanipulation of microscopic particles along the three axes using the radiation pressure generated by a focused laser beam [56] [57]. The lasers used to produce optical tweezers are continuous low power lasers ( 0.1 to $1 \mathrm{Watt}$ ). The choice of wavelength between 950 and $1060 \mathrm{~nm}$ can reduce the risk of thermal or photochemical damage. In biological applications of optical trapping and manipulation, it is possible to remotely apply controlled forces able to catch a cell or a cellular organelle, to fix it or transport it to another cell site without inflicting optical damage [58] [59]. The optical tweezers were used to study the elasticity of the red cell membrane and to better understand how the absence or abnormality of membrane proteins could lead to a permanent deformation of these cells that could lead to promote its premature destruction [60]. One of the most useful applications has been shown to be 
the measure of the forces generated by kinesin and myosin, thus resolving the issue of the mechanism of kinesin walking on the submicron microtubules, or myosin on actin strands of the cytoskeleton [61]. In a breakthrough experiment, the force generated by RNA polymerase was directly measured as it moved along a DNA molecule and transcribed an RNA strand [62].

\subsection{The Laser Ablation}

Another field is being explored using laser ablation processes in developmental biology. In this case, the aim is not the isolation of a part of the tissue but the alteration of the tissue itself. The idea is to alter a biological structure by mean of a laser, generally a pulsed laser. A series of high-precision laser ablation and microsurgical tissue removal experiments has been undertaken to test the functions of different parts of a biological system [Figure 3]. The selective removal of cells by ablation is a powerful tool in the study of eukaryotic development-
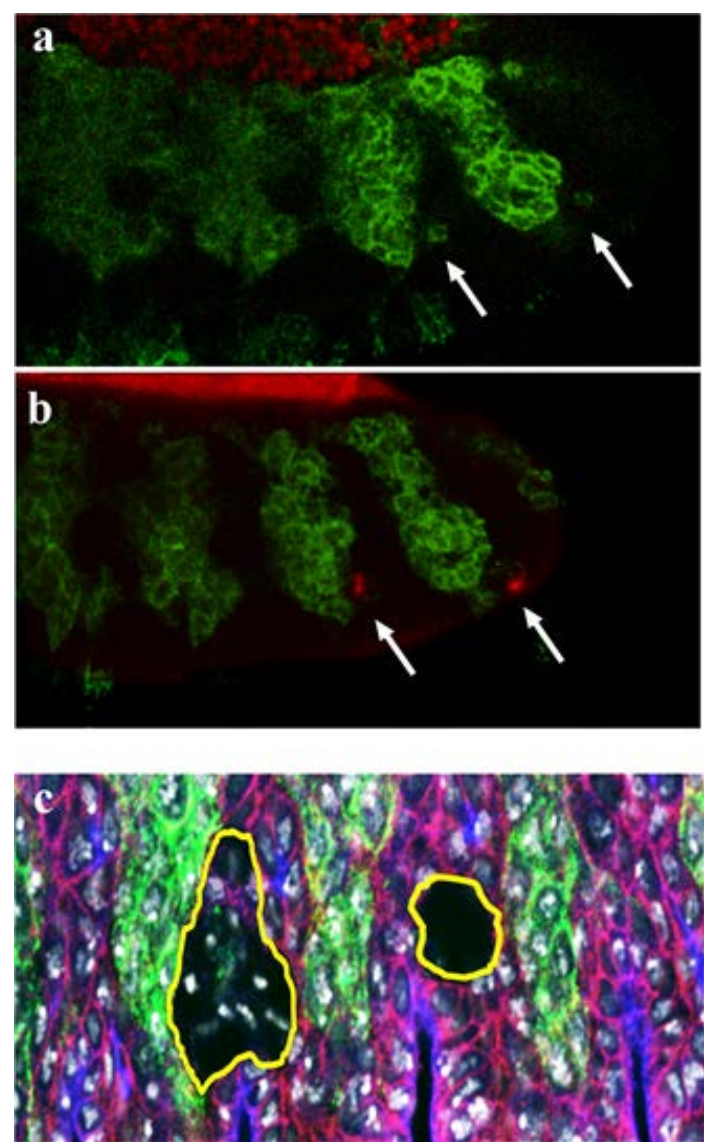

Figure 3. Ablation of two photons in drosophila embryo. The goal is to destroy specific mesodermic cells to determine if they play a mechanical role by pulling during segment grooves formation. Mesoderm is visualized in green with twist-gal4 UAS-APC2-GFP, red is autofluorescence. (with the permission of Stéphane VINCENT from CNRS UMR-5239, Laboratoire de Biologie Moléculaire de la Cellule-LBMC, Ecole Normale Supérieure, Lyon, France). (a)Target cells are visible, isolated in center (white arrow); (b) Plasma residuals are visible in red, in place of cells. (white arrow); (c) The embryo continues its development until full formation of segment grooves then fixed and stained with DAPI, GFP, anti-Disc (red) and antiaPKC (blue). Ablations are circled in yellow. 
tal biology, providing considerable information about their origin, outcome, or function in the developing organism. Most of the studies are about morphological changes induced by the ablation, for example in Drosophila [63]. These can be an infrared pulsed laser or an UV or blue pulsed laser. This kind of experiment can be performed on any laser scanning microscope but several dedicated setups are available, such as iLas ${ }^{2}$ from Roper Scientific [Figure 4], a device that provides researchers with the ability to manage and modify the position and focalization of laser light in real time, or Micropoint from ANDOR.

\subsection{The Use in Imagery}

Lasers are also used as high-resolution optoacoustic imaging modalities with great versatility in their applications, such as photoacoustic imaging (PAI), Optical Coherence Tomography (OCT) or Surface-Enhanced Raman Scattering (SERS).

- Photo-acoustic imaging is a non-invasive method. To obtain a photoacoustic effect, a short laser pulse irradiates a tissue. The energy is partially absorbed by the target and converted into heat, which generates a local transient temperature rise, followed by a local pressure rise through thermo-elastic expansion which propagate as ultrasonic waves, termed PA waves. These waves are detected by ultrasonic transducers placed outside the tissue [64]. An image is formed by determining the origins of the ultrasonic waves from their arrival times, thus essentially listening to the optical absorption contrasts of tissues. Because the intensity of a photoacoustic signal in biological tissue is proportional to optical energy absorption, which is proportional to the amount of the contrast agent [65], exogenous contrast agents are frequently needed to provide a better signal for photoacoustic imaging.

Photo-acoustic imaging uses the intrinsic chromophore, which has an optical absorption signature, as long as appropriate irradiation wavelengths are applied. It is used for example for haemoglobin [66], melanin [67], water [68] or lipid [69].

Exogenous contrast agents such as optically absorptive organic dyes (indocyanine green, Evans blue, methylene blue) or nanoparticles can enhance detection with PAI. Here gold nanoparticles have the advantage that their plasmonic properties can be used for photothermal therapy [70]. Plasmonic photothermal therapy using gold nanoparticles was described in 2004 by O'Neal et al. In this study, tumour subcutaneously xenografted in mice was intravenously injected with gold nanoshells. The tumours were then illuminated with a diode laser ( $808 \mathrm{~nm}, 4 \mathrm{~W} / \mathrm{cm}^{2}, 3 \mathrm{~min}$ ). All mice with treated tumours appeared healthy and tumour free more

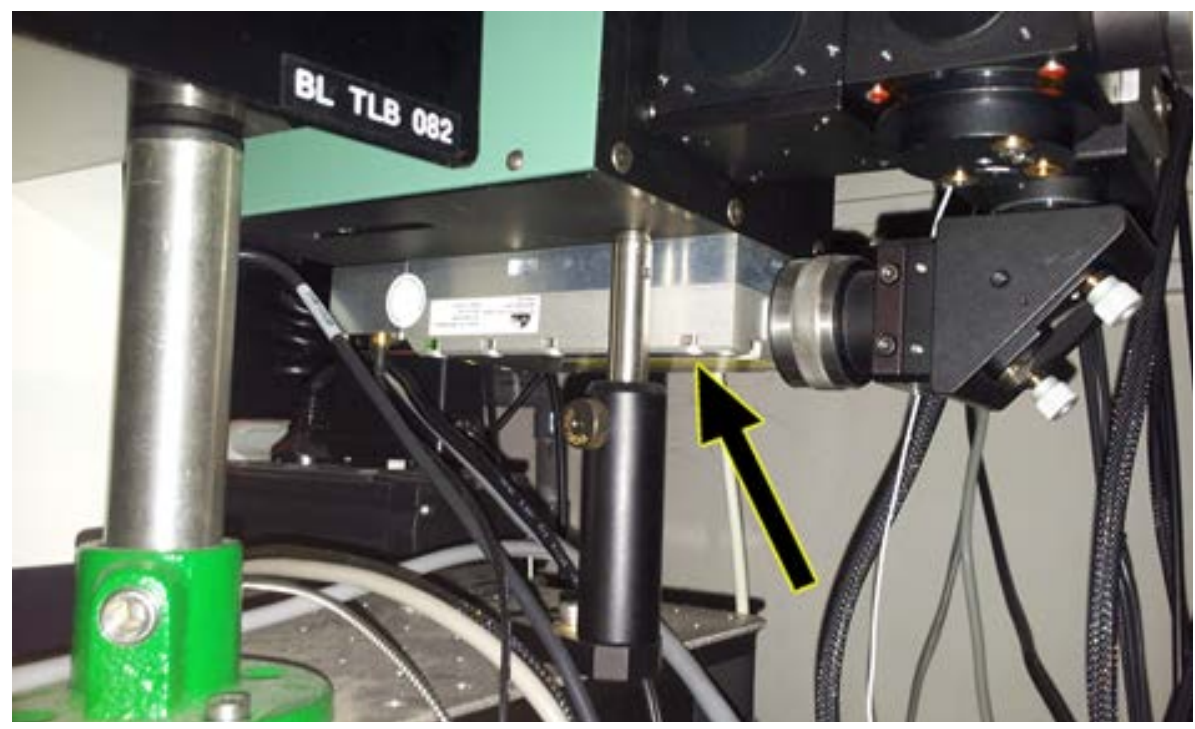

Figure 4. An experimental set-up for UV microsurgery. This iLAs ${ }^{2}$ module

[http://www.roperscientific.fr/brochures/iLas.pdf] is coupled with a homemade spinning disk confocal (black arrow). The galvanometric mirrors can drive a blue $405 \mathrm{~nm}$ diode laser (for photo-conversion or photo-activation of specific dyes; most of them are proteins like PA-GFP, Kaede, etc.), a $473 \mathrm{~nm}$ for photobleaching experiments (Fluorescence recovery after photobleaching experiments) and a $355 \mathrm{~nm}$ passively Q-Switched Nd:YAG. 
than 90 days later [71]. Laser thermal therapy with doxorubicin-loaded hollow gold nanoshells was recently used in a xenografted mouse model. Fluorescence optical imaging was used to map the release of doxorubicin and photoacoustic imaging to monitor the tumour temperature achieved during near-infrared laser-induced photothermal heating [72].

- Optical Coherence Tomography (OCT) Optical Coherence Tomography is non-invasive and the use of near-infrared light (Near-IR) enables cross-sectional images of tissues (epidermis, retina, retinal nerve fiber layer, coronary arteries, etc.) to be generated. Near-IR excitation radiation is particularly useful in biomedical studies because it enables greater penetration depths in tissues $(1-2 \mathrm{~mm})$ and a good resolution (approximately 1 - 10 micrometers) while causing less fluorescence background relative to visible radiation. The OCT system is composed of a light source (ultra-short pulsed laser, super continuum laser or super luminescent diode), an interferometer, and a microscope that delivers light and collects reflection from the tissues analyzed. OCT is a technique for imaging tissues and cells in living organisms and is a diagnostic method that is widely used in cardiology [73], ophthalmology [74], dermatology [75], and also in other medical domains such as dentistry [76].

- Surface-enhanced Raman scattering (SERS) spectroscopy is a plasmonics-based spectroscopic technique that combines laser spectroscopy with the unique optical properties of metallic nanostructures, resulting in strongly increased Raman signals when molecules are adsorbed on or near nanometer-sized structures of special metals such as gold and silver [77]. Plasmonic gold nanoparticles are used as probes for SERS imaging with different shape (nanoflowers, nanostars, nanorods, nanoshells or nanocages) and could constitute a new opening for clinical imaging.

\section{Conclusions}

In medicine, the energy delivered by the laser, whose intensity can be modulated, can cut, destroy or alter the cellular or extracellular structure of biological tissue. In addition, laser applications have the advantage of reducing the risk of infection and promoting healing. Now integrated in surgical procedures, for a better focus and precise cutting, laser surgery is not however without risks for pregnancy or contra-indications for the use of photosensitizing drug.

In biology, the complexity of tissue makes the results of "classic" biological analyses often difficult to interpret. The laser is an effective tool for destroying cancer cells. However, high power lasers act indiscriminately and thus destroy cancer cells but also the surrounding tissue. This property is a crucial tool in the laser microdissection technique when you want to conduct molecular analysis in a region of interest with the ability to selectively destroy contaminating cells. Indeed, the aim of this technology is to overcome the cellular heterogeneity present in all biological tissues and to facilitate its study on a well-defined cell population. In this sense, laser microdissection has greatly contributed to the evolution of research to understand physiological mechanisms which can now be clearly demonstrated on the level of a specific cell population, and even on the level of the single cell.

It is now well known that functional tissue engineering is a major factor in the biology of development [78]. What happens if you cut an actin fiber network during a cell division? Is a drosophila embryo stable if you kill a cell during the folding process [79]? What are the parameters involved in the meristematic zone of a developing plant [80]? All these questions are addressed using lasers.

A variety of nanostructures have emerged possessing properties suitable for a range of biological applications. Important classes of nanostructures include quantum dots, such as tiny light-emitting particles on the nanometer scale, useful for highly sensitive cellular imaging [81] [82], magnetic nanoparticules used for clinical applications [83] [84], polymeric particules to encapsulated therapeutic molecules and metallic nanoparticules. The development of nanotechnologies has revolutionized the mode of drug administration. The design of nanoparticle suspensions loaded with drugs can increase the therapeutic index of many compounds (increased solubility, improved efficiency, reduced toxicity) by selectively targeting diseased tissues and cells. They enable the delivery of the active molecule, but also controlled release of the active ingredient in response to an external stimulus [85]. Nanotheranostic is a further experimental approach that gives dual functionality to the nanoparticles, coupling a drug, the therapy, and an imaging agent, the diagnostic vector, and this opens the way to tailored-patient treatments. This has been demonstrated in vivo by Huang et al. [86].

The use of lasers in medicine and biology has demonstrated its interest through innovative advanced technol- 
ogies such as laser microdissection and/or photoablation which at different levels of expression enable understanding of the physiological mechanisms in the evolution of a disease. The results will help establish better diagnosis and treatments tailored to each patient, as well as the development of nanotechnology in close connection with the technological advances in the field of imaging which will help not only in diagnosis but also in the possible application of minimally invasive treatment protocols. Nanomedicine is a promising new form of medication for the treatment of certain cancers, infectious diseases or for diagnosis. Important results have already passed the stage of new engineering, and drugs are now available to patients for the treatment of ovarian cancer $\left(\right.$ Doxil $\left.^{\circledR}\right)$, Kaposi sarcoma (Daunoxome ${ }^{\circledR}$ ), or infectious diseases (Ambisome ${ }^{\circledR}$ ).

\section{Acknowledgements}

Authors are gratefully indebted to Dr Philippe Ratajczak for critical reading and helpful discussions, to Marie-France Cavy for graphical assistance. We also thank Angela Swaine-Verdier for kindly editing the manuscript.

\section{References}

[1] Zaret, M.M., Breinin, G.M., Schmidt, H., Ripps, H., Siegel, I.M. and Solon, L.R. (1961) Science, 134, 1525-1526. http://dx.doi.org/10.1126/science.134.3489.1525

[2] Avedisian, C.T., Cavicchi, R.E., McEuen, P.L. and Zhou, X. (2009) Annals of the New York Academy of Sciences, 1161, 62-73. http://dx.doi.org/10.1111/j.1749-6632.2009.04090.x

[3] Moo-Young, G.A. (1985) Western Journal of Medicine, 143, 745-750.

[4] Anderson, R.R. (2013) Journal of Investigative Dermatology, 133, E21-E23.

[5] Herd, R. (1996) JAMA Dermatology, 132, 1262-1262. http://dx.doi.org/10.1001/archderm.1996.03890340128035

[6] Lehnert, M.W. (1996) Northwest Dentistry, 75, 17-22.

[7] Fan, C.M. and Rox-Anderson, R. (2008) Phlebology, 23, 206-213. http://dx.doi.org/10.1258/phleb.2008.008049

[8] Mahar, P.S. and Jamali, K.K. (2008) Journal of the College of Physicians and Surgeons Pakistan, 18, 102-104.

[9] Folk, J.C., Shortt, S.G. and Kleiber, P.D. (1985) Ophthalmology, 92, 100-108. http://dx.doi.org/10.1016/S0161-6420(85)34083-6

[10] Sattayut, S., Nakkyo, P., Phusrinuan, P., Sangiamsak, T. and Phiolueang, R. (2013) Laser Therapy, 22, 11-15. http://dx.doi.org/10.5978/islsm.13-OR-02

[11] Garrett, A.B., Dufresne Jr., R.G., Ratz, J.L. and Berlin, A.J. (1990) Journal of Dermatologic Surgery \& Oncology, 16, 737-740.http://dx.doi.org/10.1111/j.1524-4725.1990.tb00112.x

[12] Bernstein, L.J., Kauvar, A.N., Grossman, M.C. and Geronemus, R.G. (1998) Dermatologic Surgery, 24, 101-107. http://dx.doi.org/10.1111/j.1524-4725.1998.tb04060.x

[13] Wesley, R.E. and Bond, J.B. (1985) Ophthalmic Surgery, 16, 631-633.

[14] Mahajan, R.S., Shah, A.C., Nagar, A. and Freny, B.E. (2013) Journal of Cutaneous and Aesthetic Surgery, 6, $161-163$. http://dx.doi.org/10.4103/0974-2077.118423

[15] Bonan, P., Campolmi, P., Cannarozzo, G., Bruscino, N., Bassi, A., Betti, S. and Lotti, T. (2012) Journal of the European Academy of Dermatology and Venereology, 26, 186-193.

http://dx.doi.org/10.1111/j.1468-3083.2011.04034.x

[16] Metelitsa, A.I. and Alster, T.S. (2010) Dermatologic Surgery, 36, 299-306. http://dx.doi.org/10.1111/j.1524-4725.2009.01434.x

[17] Polla, L.L., Tan, O.T., Garden, J.M. and Parrish, J.A. (1987) Dermatologica, 174, 11-17. http://dx.doi.org/10.1159/000248973

[18] Scheepers, J.H. and Quaba, A.A. (1995) Journal of Pediatric Surgery, 30, 101-104. http://dx.doi.org/10.1016/0022-3468(95)90621-5

[19] Oram, Y., Karincaoglu, Y., Koyuncu, E. and Kaharaman, F. (2010) Dermatologic Surgery, 36, 377-381. http://dx.doi.org/10.1111/j.1524-4725.2009.01448.x

[20] Taibjee, S.M., Cheung, S.T., Laube, S. and Lanigan, S.W. (2005) British Journal of Dermatology, 153, 960-966. http://dx.doi.org/10.1111/j.1365-2133.2005.06827.x 
[21] Dierickx, C.C., Grossman, M.C., Farinelli, W.A. and Anderson, R.R. (1998) JAMA Dermatology, 134, 837-842. http://dx.doi.org/10.1001/archderm.134.7.837

[22] Grunewald, S., Bodendorf, M.O., Zygouris, A., Simon, J.C. and Paasch, U. (2014) Lasers in Surgery and Medicine, 46, 13-19.

[23] Elkin, Z., Ranka, M.P., Kim, E.T., Kahanowicz, R. and Whitmore, W.G. (2011) Clinical Ophthalmology, 5, $1733-1735$. http://dx.doi.org/10.2147/OPTH.S26035

[24] Hovenic, W. and Golda, N. (2012) Dermatologic Surgery, 38, 2031-2034. http://dx.doi.org/10.1111/j.1524-4725.2012.02536.x

[25] Maluki, A.H. and Mohammad, F.H. (2012) Journal of Cosmetic and Laser Therapy, 14, 224-233. http://dx.doi.org/10.3109/14764172.2012.723807

[26] Fornaini, C. (2013) Laser Therapy, 22, 31-35. http://dx.doi.org/10.5978/islsm.13-OR-04

[27] Hibst, R. and Keller, U. (1989) Lasers in Surgery and Medicine, 9, 338-344. http://dx.doi.org/10.1002/lsm.1900090405

[28] Kahn, A.M. and Applebaum, R. (2011) Ophthalmic Plastic \& Reconstructive Surgery, 27, 132-134. http://dx.doi.org/10.1097/IOP.0b013e3181e173ad

[29] Mallur, P.S., Tajudeen, B.A., Aaronson, N., Branski, R.C. and Amin, M.R. (2011) Laryngoscope, 121, 590-595. http://dx.doi.org/10.1002/lary.21354

[30] Bernstein, E.F., Noyaner-Turley, A. and Renton, B. (2014) Lasers in Surgery and Medicine, 46, 81-88.

[31] Angiero, F., Buccianti, A., Parma, L. and Crippa, R. (2013) Lasers in Medical Science, (c) Springer-Verlag, London. http://dx.doi.org/10.1007/s10103-013-1401-7

[32] Matlach, J., Kasper, K., Kasper, B. and Klink, T. (2013) European Journal of Ophthalmology, 23, 431-435. http://dx.doi.org/10.5301/ejo.5000242

[33] Golan, S. and Kurtz, S. (2013) Journal of Glaucoma, 2014 @ by Lippincott Williams \& Wilkins. http://dx.doi.org/10.1097/IJG.0b013e31829da1ba

[34] Anderson, R.R. and Parrish, J.A. (1983) Science, 220, 524-527. http://dx.doi.org/10.1126/science.6836297

[35] Wall, T.L. (2007) Seminars in Plastic Surgery, 21, 147-158. http://dx.doi.org/10.1055/s-2007-991183

[36] Tsagkataki, M., Tey, A., Ramasamy, B., Anijeet, D. and Kaye, S.B. (2013) Clinical \& Experimental Ophthalmology. http://dx.doi.org/10.1111/ceo.12146

[37] Danieliene, E., Gabryte, E., Danielius, R., Vengris, M., Vaiceliunaite, A., Morkunas, V. and Ruksenas, O. (2013) Journal of Cataract \& Refractive Surgery, 39, 258-267. http://dx.doi.org/10.1016/j.jcrs.2012.09.022

[38] Asrani, S., Zou, S., D’Anna, S., Phelan, A., Goldberg, M. and Zeimer, R. (1996) Investigative Ophthalmology \& Visual Science, 37, 1642-1650.

[39] Bertheau, P., Meignin, V. and Janin, A. (1998) Annales de Pathologie, 18, 110-119.

[40] Simone, N.L., Bonner, R.F., Gillespie, J.W., Emmert-Buck, M.R. and Liotta, L.A. (1998) Trends in Genetics, 14, 272276. http://dx.doi.org/10.1016/S0168-9525(98)01489-9

[41] Legrès, L.G., Masselon, C., Janin, A. and Bertheau, P. (2014) American Journal of Cancer Research, 4, 1-28.

[42] Emmert-Buck, M.R., Bonner, R.F., Smith, P.D., Chuaqui, R.F., Zhuang, Z., Goldstein, S.R., Weiss, R.A. and Liotta, L.A. (1996) Science, 274, 998-1001. http://dx.doi.org/10.1126/science.274.5289.998

[43] Bohm, M., Wieland, I., Schutze, K. and Rubben, H. (1997) American Journal of Pathology, 151, 63-67.

[44] Kolble, K. (2000) Journal of Molecular Medicine, 78, B24-B25.

[45] Böhm, M., Schmidt, C., Wieland, I. and Leclerc, N. (1999) Onkologie, 22, 296-301. http://dx.doi.org/10.1159/000026978

[46] Vogel, A., Horneffer, V., Lorenz, K., Linz, N., Huttmann, G. and Gebert, A. (2007) Methods in Cell Biology, 82, 153205.http://dx.doi.org/10.1016/S0091-679X(06)82005-4

[47] De Spiegelaere, W., Filliers, M. and Van Soom, A. (2012) Single-Cell Analysis. Methods in Molecular Biology, 853, 29-37. http://dx.doi.org/10.1007/978-1-61779-567-1_4

[48] Sethi, S., Vrana, J.A., Theis, J.D., Leung, N., Sethi, A., Nasr, S.H., Fervenza, F.C., Cornell, L.D., Fidler, M.E. and Dogan, A. (2012) Kidney International, 82, 226-234.http://dx.doi.org/10.1038/ki.2012.108

[49] Bertheau, P., Plassa, L.F., Lerebours, F., de Roquancourt, A., Turpin, E., Lidereau, R., de The, H. and Janin, A. (2001) Laboratory Investigation, 81, 1397-1402. http://dx.doi.org/10.1038/labinvest.3780353

[50] Hu, L., Sham, J.S., Tjia, W.M., Tan, Y.Q., Lu, G.X. and Guan, X.Y. (2004) Genomics, 83, 298-302. 
http://dx.doi.org/10.1016/j.ygeno.2003.08.021

[51] Von Eggeling, F., Melle, C. and Ernst, G. (2007) Proteomics, 7, 2729-2737. http://dx.doi.org/10.1002/pmic.200700079

[52] Ko, Y., Hahn, T., Lu, H., Ma, Z.L., Chen, J., Rothe, M., Florin, A., Fronhoffs, S., Albers, P., Sachinidis, A., Vetter, H., Kaminski, A., Behrens, P., Wellmann, A. and Wernert, N. (2005) Journal of Molecular Medicine, 15, 183-196.

[53] Vandewoestyne, M. and Deforce, D. (2010) International Journal of Legal Medicine, 124, 513-521. http://dx.doi.org/10.1007/s00414-010-0499-4

[54] Sanders, C.T., Sanchez, N., Ballantyne, J. and Peterson, D.A. (2006) Journal of Forensic Sciences, 51, 748-757. http://dx.doi.org/10.1111/j.1556-4029.2006.00180.x

[55] Elliott, K., Hill, D.S., Lambert, C., Burroughes, T.R. and Gill, P. (2003) Forensic Science International, 137, 28-36. http://dx.doi.org/10.1016/S0379-0738(03)00267-6

[56] Ashkin, A. (1997) Proceedings of the National Academy of Sciences of the United States of America, 94, 4853-4860. http://dx.doi.org/10.1073/pnas.94.10.4853

[57] Lee, M.P. and Padgett, M. (2012) Journal of Microscopy, 248, 219-222. http://dx.doi.org/10.1111/j.1365-2818.2012.03639.x

[58] Hawes, C., Osterrieder, A., Sparkes, I.A. and Ketelaar, T. (2010) Current Opinion in Plant Biology, 13, 731-735. http://dx.doi.org/10.1016/j.pbi.2010.10.004

[59] Leitz, G., Weber, G., Seeger, S. and Greulich, K.O. (1994) Physiological Chemistry \& Physics \& Medical NMR, 26, 69-88.

[60] Sleep, J., Wilson, D., Simmons, R. and Gratzer, W. (1999) Biophysical Journal, 77, 3085-3095. http://dx.doi.org/10.1016/S0006-3495(99)77139-0

[61] Ashkin, A., Schutze, K., Dziedzic, J.M., Euteneuer, U. and Schliwa, M. (1990) Nature, 348, 346-348. http://dx.doi.org/10.1038/348346a0

[62] Gelles, J. and Landick, R. (1998) Cell, 93, 13-16. http://dx.doi.org/10.1016/S0092-8674(00)81140-X

[63] Sweeney, S.T., Hidalgo, A., de Belle, J.S. and Keshishian, H. (2012) Cold Spring Harbor Protocols, 2012, 691-693.

[64] Yao, J. and Wang, L.V. (2011) Contrast Media \& Molecular Imaging, 6, 332-345. http://dx.doi.org/10.1002/cmmi.443

[65] Rajian, J.R., Carson, P.L. and Wang, X. (2009) Optics Express, 17, 4879-4889. http://dx.doi.org/10.1364/OE.17.004879

[66] Zhang, H.F., Maslov, K., Stoica, G. and Wang, L.V. (2006) Nature Biotechnology, 24, 848-851. http://dx.doi.org/10.1038/nbt1220

[67] Zhang, Y., Cai, X., Choi, S.W., Kim, C., Wang, L.V. and Xia, Y. (2010) Biomaterials, 31, 8651-8658. http://dx.doi.org/10.1016/j.biomaterials.2010.07.089

[68] Xu, Z., Li, C. and Wang, L.V. (2010) Journal of Biomedical Optics, 15, Article ID: 036019. http://dx.doi.org/10.1117/1.3443793

[69] Allen, T.J., Hall, A., Dhillon, A.P., Owen, J.S. and Beard, P.C. (2012) Journal of Biomedical Optics, 17, Article ID: 061209. http://dx.doi.org/10.1117/1.JBO.17.6.061209

[70] Young, J.K., Figueroa, E.R. and Drezek, R.A. (2012) Annals of Biomedical Engineering, 40, 438-459. http://dx.doi.org/10.1007/s10439-011-0472-5

[71] O’Neal, D.P., Hirsch, L.R., Halas, N.J., Payne, J.D. and West, J.L. (2004) Cancer Letters, 209, 171-176. http://dx.doi.org/10.1016/j.canlet.2004.02.004

[72] Lee, H.J., Liu, Y., Zhao, J., Zhou, M., Bouchard, R.R., Mitcham, T., Wallace, M., Stafford, R.J., Li, C., Gupta, S. and Melancon, M.P. (2013) Journal of Controlled Release, 172, 152-158. http://dx.doi.org/10.1016/j.jconrel.2013.07.020

[73] Gutierrez-Chico, J.L., Alegria-Barrero, E., Teijeiro-Mestre, R., Chan, P.H., Tsujioka, H., de Silva, R., Viceconte, N., Lindsay, A., Patterson, T., Foin, N., Akasaka, T. and di Mario, C. (2012) European Heart Journal-Cardiovascular Imaging, 13, $370-$ 384. http://dx.doi.org/10.1093/ehjci/jes025

[74] Adhi, M. and Duker, J.S. (2013) Current Opinion in Ophthalmology, 24, 213-221. http://dx.doi.org/10.1097/ICU.0b013e32835f8bf8

[75] Sattler, E., Kastle, R. and Welzel, J. (2013) Journal of Biomedical Optics, 18, Article ID: 061224. http://dx.doi.org/10.1117/1.JBO.18.6.061224

[76] Holtzman, J.S., Osann, K., Pharar, J., Lee, K., Ahn, Y.C., Tucker, T., Sabet, S., Chen, Z., Gukasyan, R. and Wilder, P. (2010) Lasers in Surgery and Medicine, 42, 752-759. http://dx.doi.org/10.1002/lsm.20963

[77] Vo-Dinh, T., Yan, F. and Stokes, D.L. (2005) Methods in Molecular Biology, 300, 255-283.

[78] Mammoto, T., Mammoto, A. and Ingber, D.E. (2013) Annual Review of Cell and Developmental Biology, $29,27-61$. http://dx.doi.org/10.1146/annurev-cellbio-101512-122340 
[79] Lynch, H.E., Crews, S.M., Rosenthal, B., Kim, E., Gish, R., Echiverri, K. and Hutson, M.S. (2013) Developmental Biology, 384, 205-213. http://dx.doi.org/10.1016/j.ydbio.2013.10.005

[80] Reinhardt, D., Frenz, M., Mandel, T. and Kuhlemeier, C. (2003) Development, 130, 4073-4083. http://dx.doi.org/10.1242/dev.00596

[81] Gao, X. and Dave, S.R. (2007) Advances in Experimental Medicine and Biology, 620, 57-73. http://dx.doi.org/10.1007/978-0-387-76713-0_5

[82] Ho, Y.P. and Leong, K.W. (2010) Nanoscale, 2, 60-68. http://dx.doi.org/10.1039/b9nr00178f

[83] Johannsen, M., Thiesen, B., Wust, P. and Jordan, A. (2010) International Journal of Hyperthermia, 26, 790-795. http://dx.doi.org/10.3109/02656731003745740

[84] Thiesen, B. and Jordan, A. (2008) International Journal of Hyperthermia, 24, 467-474. http://dx.doi.org/10.1080/02656730802104757

[85] Couvreur, P. (2012) Biologie Aujourd'hui, 206, 237-248. http://dx.doi.org/10.1051/jbio/2012025

[86] Huang, X., El-Sayed, I.H., Qian, W. and El-Sayed, M.A. (2006) Journal of the American Chemical Society, 128, 21152120. http://dx.doi.org/10.1021/ja057254a 